\title{
OCORRÊNCIA DE Cryptosporidium spp. EM SUÍNOS (Sus scrofa domesticus) CRIADOS DE MANEIRA EXTENSIVA
}

(Ocurrence of Cryptosporidium spp. in pigs (Sus scrofa domesticus) created extensively)

\author{
Ricardo Babinski Bregonde, Vinicius Dahm, Ana Paula Molinari Candeias, Daniela Borges da Cruz, Nelson Luis \\ Mello Fernandes, Silvia Cristina Osaki \\ Universidade Federal do Paraná, Palotina, Paraná, Brasil.
}

*Correspondência: sil_osaki@ufpr.br

RESUMO: A criptosporidiose é uma doença parasitária, causada por coccídios do gênero Cryptosporidium, podendo acometer uma gama de animais, inclusive os suínos. A doença leva a perda do epitélio intestinal e vilosidades, resultando em diminuição na absorção de nutrientes e consequentemente, perdas na cadeia produtiva (LIMA, 2018). É uma enfermidade de caráter zoonótico, sendo ocasionada nos seres humanos principalmente pelo Cryptosporidium parvum, levando a quadros assintomáticos, ou a sintomas de diarreia, náuseas, vômito e tosse (ROSSI et al., 2014). Em pacientes imunocomprometidos, causa enterite grave, podendo ser fatal, caracterizando um grave problema de saúde pública. Essa mesma espécie é a principal responsável pela infecção em diversos animais domésticos e silvestres, demonstrando assim a importância da doença em um contexto de Saúde Única. Pesquisar a ocorrência de Cryptosporidium spp. em fezes de suínos criados de maneira extensiva no município de Toledo, região Oeste do estado do Paraná, Brasil. As coletas foram realizadas em duas propriedades rurais distintas, localizadas no município de Toledo. Ambas as propriedades possuíam instalações simples, ausência de manejo antiparasitário e ausência de tratamento dos excrementos dos animais. Dez amostras fecais foram colhidas diretamente da ampola retal dos animais, sendo seis amostras da primeira propriedade e quatro da segunda propriedade. As amostras foram armazenadas em frascos com tampa rosca, refrigeradas e analisadas em até 48 horas. Para a detecção dos oocistos do protozoário, foi utilizada a técnica de Ziehl-Neelsen modificado. Dos dez animais testados, apenas dois demonstraram positividade para o protozoário (20\%) na técnica utilizada. Ambos os animais positivos eram oriundos da primeira propriedade. A presença do protozoário nos animais nas propriedades avaliadas neste estudo indica um risco de contaminação de animais e seres humanos que convivem e manejam os mesmos, bem como, uma possível contaminação ambiental do solo e afluentes. É importante recomendar nestes casos, a adoção de manejo antiparasitário nos animais e destinação correta dos excrementos, de modo a objetificar a eliminação da infecção parasitária nos animais. Diminuindo dessa forma, as chances de infecção de outros animais, do ambiente e do homem.

Palavras-chave: coccídios; criptosporidiose; protozoário; saúde única

Agradecimentos

Ao laboratório de Doenças Parasitárias, ao laboratório de Saúde Única da Universidade Federal do Paraná - Setor Palotina e ao CNPq.

Nota de aprovação pelo Comitê de Ética

O estudo foi aprovado pela Comissão de Ética no Uso de Animais da Universidade Federal do Paraná, com protocolo número 25/2017.

\section{Referências}

LIMA, V. F. S. Agentes parasitários em animais silvestres, sinantrópicos e domésticos: aspectos clínicos, epidemiológicos e de saúde pública. 2018. Tese (Programa de Pós-Graduação em Ciência Animal Tropical) - Universidade Federal Rural de Pernambuco, Recife, 2018.

ROSSI, G. A. M. et al. Zoonoses parasitárias veiculadas por alimentos de origem animal: revisão sobre a situação no Brasil. Arquivos do Instituto Biológico, v. 81, n. 3, p. 290-298, set. 2014. 